\title{
Mouse Embryonic Stem Cells Basics from a Fertilized Zygote to These Promising Pluripotent Stem Cells
}

\author{
Carol Fagundez, Mónica Loresi, Stella Delcourt and Pablo Argibay \\ Instituto de Ciencias Básicas y Medicina Experimental - Hospital Italiano de Buenos Aires \\ Argentina
}

\section{Introduction}

The intention of this chapter is to provide an overview of mouse embryonic stem cells, presenting useful and practical advice to those working in this field, including some personal experience of the authors in this topic.

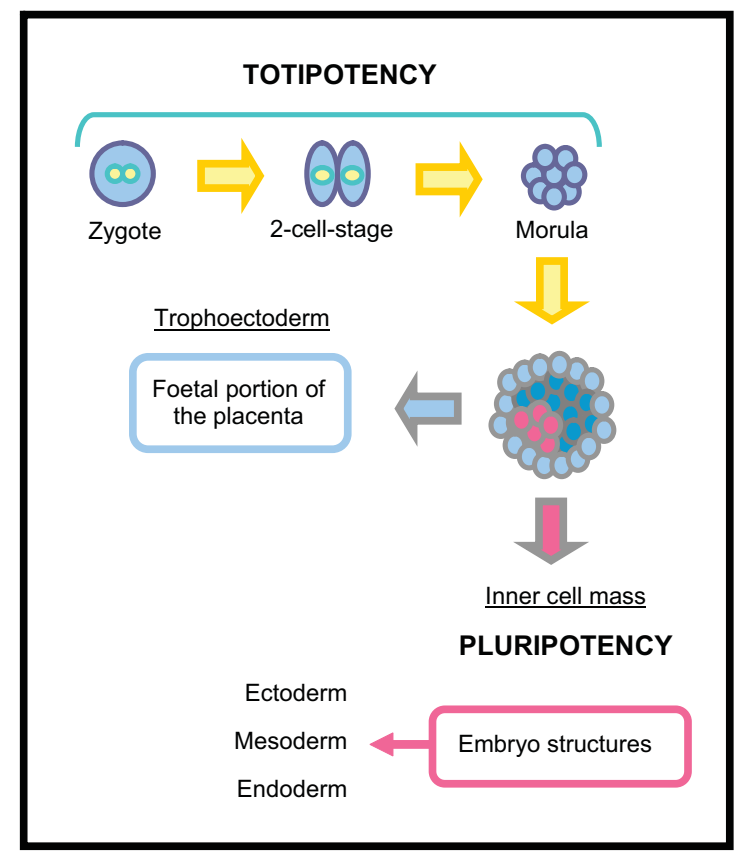

Fig. 1. Origin of mouse embryonic stem cells

In mammals, the fertilized oocyte generates a complex organism containing about 200 types of specialized somatic cells (Wobus, 2001). The zygote is considered the first entity of life and has the ability to produce an entire organism. This property, known as totipotency, is 
maintained until morula stage (Wobus and Boheler, 2005). By the time the embryo reaches blastocysts stage, at 3.5 days post coitum (dpc), it gets through its first differentiation giving rise to two well-defined cell populations, the trophoectoderm (TE) and the inner cell mass (ICM). The TE is an epithelial monolayer of cells externally located responsible for the foetal portion of the placenta and enclosures a hollowed fluid-filled cavity called blastocoele which contains the ICM, a compacted group of cells known to be the source of stem cells. The ICM will in turn originate every part of the embryo along with extraembryonic membranes like the allantois and the amnion. Before implantation occurs, the primitive endoderm differentiates on the blastocoelic surface of the ICM, producing the endoderm layer of the yolk sac (Fig.1) (Rossant, 2001; Sherman, 1975a).

\section{First attempts to isolate pluripotent cells}

Some decades ago, researchers used to think that the uterus emitted signals which triggered various events responsible for the differentiation of the embryo. Early efforts to investigate this matter involved removing embryos from the mice female tract prior to implantation and reimplanting them in a variety of foreign sites. Some of these experiments were successful and suggested that differentiation of a number of embryonic cell types could be carried out outside the uterus demonstrating that these events do not necessarily depend on the maternal environment. Posterior efforts were made to achieve proper conditions for the establishment of blastocysts culture. Short-term blastocysts culture was achieved by some researchers from 1965 to 1966 (Gwatkin, 1966; Cole and Paul, 1965). These authors reported that the trophoectoderm layer developed into giant cells resembling the in vivo trophoblast, but the ICM failed to proliferate or even survive beyond a few days, but in some isolated cases a limited proliferation of ICM cells in $5-20 \%$ of the blastocysts cultured was obtained (Sherman, 1975a).

The first success at long-term culture of mouse blastocysts was reported in 1975 by Sherman (Sherman, 1975b), who was able to grow trophoblast cells and even ICM cells in culture for several months. A cell line from these cells was obtained, but it was poorly tumorigenic, and when tumours were produced, they showed a low degree of differentiation. Moreover, blastocyst-derived cell lines did not possess stable diploid chromosome number and they eventually became hypotetraploid (Sherman, 1975a).

The first pluripotent cell lines to be established were embryonal carcinoma cell (ECC) lines, derived from the undifferentiated compartment of murine and human germ cell tumours. These cells shared morphological, biochemical and immunological properties with pluripotent embryonic stem cells. In some cases, these properties included the ability to differentiate in vitro into derivatives of the three germ layers: endoderm, mesoderm and ectoderm, similarly to the isolated embryonic inner cell mass (ICM). The stem cells taken from these lines could participate in the development of completely normal adult mice when injected into blastocyst-stage embryos (Martin, 1981). However, ECCs showed chromosomal aberrations, they also lost their ability to differentiate and chemical inducers were necessary to trigger differentiation under in vitro conditions. Another disadvantage was the fact that ECCs sporadically colonized the germ cell line when performing the blastocyst injection technique. These data suggested that ECCs did not retain the pluripotency shown by early embryonic cells. It was necessary then, to find a proper source of stable pluripotent cells destined to a diversity of applications (Rippon and Bishop, 2004; Wobus and Boheler, 2005). 
In 1981, Evans and Kaufman successfully isolated pluripotent cells of pre-implantation embryos from $129 \mathrm{SvE}$ strain mice, obtaining a line with normal karyotype, capable of producing teratocarcinomas and forming embryoid bodies (EBs) which eventually, differentiated into a complex of tissues. The authors termed these cells "EK", to distinguish them from ECCs, of similar properties (Evans and Kaufman, 1981). A few months later, Martin published his results about the establishment of a pluripotent cell line derived from the isolated ICM of mouse embryos cultured in presence of ECC conditioned medium. These cells showed all the essential features of teratocarcinoma stem cells. These results lead to researchers to think that the medium conditioned by teratocarcinoma stem cells owned a factor, perhaps identical to a normal endogenous embryonic growth factor, capable of stimulating the proliferation of a small population of pluripotent cells in the normal embryo. The term "embryonic stem cell" (ESC) was introduced by Martin to denote the origin of these cells from embryos and to make a distinction from the ECC derived from teratocarcinomas (Martin, 1981).

In 1984, Wobus et al. reproduced some experiments with mouse embryonic stem cells (mESCs) demonstrating its requirements of a fresh and good quality feeder layer of murine embryonic fibroblasts (MEFs), since long-term culture without its presence was not possible. In this work, the authors also proved that these cells express high alkaline phosphatase activity (Wobus et al., 1984).

\section{Considerations at the moment of working with mESCs}

There are several factors to consider for successful isolation and maintenance of good quality ESCs, such as the culture media employed, the reagents used for supplementation and the feeder cells, among others.

Supplements for the culture medium are very important for the establishment of mESCs, and the leukaemia inhibitory factor (LIF) is known to be essential (Deacon et al., 1998). Maintenance of the stem cell phenotype in vitro requires the presence of a feeder layer of fibroblasts or a soluble factor with a differentiation inhibitory activity (DIA). In the absence of DIA the embryonic stem cells differentiate into a wide range of cell types. In 1988, Williams et al. purified the myeloid leukaemia inhibitory factor, a haematopoietic regulator, which shows several similarities with DIA (Smith et al., 1988; Williams et al., 1988), and could substitute it in the conservation of pluripotent ESCs lines. These authors assayed different ESCs lines for their performance under the presence of LIF and noted that the proportion of mESCs colonies having a stem cell phenotype was related to the concentration of LIF in the culture (Williams et al., 1988). The examination of ESCs over a range of LIF concentrations has demonstrated that supplementation of ESC medium with LIF had little effect on growth rates, but it significantly diminished the probability of cells to undergo differentiation (Zandstra et al., 2000). Apparently, the volume of LIF necessary for the efficient derivation of mESCs is influenced by genetic diversity (Baharvand and Matthaei, 2004; Tanimoto et al., 2008).

The leukaemia inhibitory factor is a secreted polypeptide cytokine that inhibits the spontaneous differentiation of ESCs and is produced by both, MEFs and STO cells. Mouse ESCs can be cultured without feeder cells in gelatine-coated plates when medium is supplemented with purified LIF. Under such conditions, mESCs may go through a "crisis" in which colonies flatten and differentiation begins at the edges of the colony. After a few passages, a good morphology may appear and sublines from these cells can be derived with 
normal morphology under these circumstances. However, since MEF and STO cells are probably secreting other factors, besides LIF, that enhance the survival or growth of ESCs, most laboratories continue to use feeder cells and medium supplemented with LIF (Nagy et al., 2003).

The culture media used for the establishment of ESCs usually contain serum, which includes various unknown substrates that affect cell viability and properties (Lee et al., 2006). Foetal bovine serum (FBS) is a vital supplement, but contains a variety of pro-differentiation factors which can affect the propagation of undifferentiated ESCs (Bryja et al., 2006; Tanimoto et al., 2008). These factors potentially generate heterogeneity in ESCs cultures, which results in differential responses of individual stem cells batches to the same culture environment and differentiation signals. For this reason many researchers have decided to introduce a synthetic serum (KoSR, knockout serum replacement) in their protocols to substitute FBS. It is known that KoSR does not contain any undefined growth factors or differentiation promoting factors. Therefore, the use of this serum instead of FBS eliminates some of the variability of the ESCs establishment system (Lee et al., 2006).

According to Lee et al. partial or whole replacement of FBS with KoSR not only suppresses ICM cell differentiation but also enhances colony formation. These results imply that FBS replacement reduces or eliminates the differentiation factors from the culture environment, which might be included in the FBS. Moreover, KoSR may contain a factor that promotes ICM cell proliferation and results in efficiency colony formation as shown by Tanimoto et al. who obtained a higher rate of ES-like colony generation when ES medium was supplemented with KoSR (Lee et al., 2006; Tanimoto et al., 2008).

Bryja et al. observed that ES medium containing KoSR did not support growth of trophoblast cells. It seems that the slower growth and increased degeneration of trophoblastic cells can be an important factor favouring growth of ESCs within the blastocyst, and this synthetic serum appears to selectively favour the growth of embryonic stem cells at the expense of other cell types within the blastocyst (Bryja et al., 2006).

Apparently, mESCs cultured under KoSR show low Erk kinase activation. Some experiments have shown that loss of Erk2 suppresses differentiation in embryonic stem cells. Erk inhibition was reported to allow the derivation of mESCs even from nonpermissive mouse strains, and one possibility is that KoSR maintains the activity of this enzyme at low levels, facilitating mES cells isolation (Bryja et al., 2006; Buehr and Smith, 2003; Masui, 2010).

Some authors have attempted supplementation of ES medium with a FBS-KoSR mixture in different ratios to improve the isolation and the subsequent establishment of ESCs (Lee et al., 2006; Tanimoto et al., 2008). However, culture in ES medium without complete or partial FBS replacement do not always support ESCs derivation, but could be beneficial to increase cell growth rate of the colonies already established, while preserving the stemness state (Fagundez et al., 2009; Lee et al., 2006).

The use of KoSR could be useful to easily isolate mESCs from cultures of whole blastocyst embryos, since it prevents development of trophoblastic cells which tend to colonize the culture, avoiding also the application of immunosurgery, a complex technique involving the use of cytotoxic antibodies, that is not always efficient at the moment of eliminating all the trophoblastic cell population of the embryo (Fagundez et al., 2009; Gardner, 1985).

The original protocols of mESCs isolation involve the employment of high-glucose DMEM as culture medium. In the recent years many researchers have replaced this medium by a knockout version (Ko-DMEM), of reduce osmolarity. The difference between DMEM and Ko- 
DMEM in supporting the subculturing of ICM cell-derived colonies probably implies that the inorganic salt composition of the basal medium affects ES cell maintenance (Lee et al., 2006).

Tanaka et al. isolated the ICM of blastocysts by lasser dissection and cultured them under the standard culture medium (DMEM + FBS) and a knockout medium (Ko-DMEM + KoSR) obtaining a higher efficiency employing the second alternative (17.5\% over $1.6 \%)$. This alternative culture media, also employed by Bryja et al., demonstrated to be suitable for the establishment of ESCs lines in a feeder cell-free system. The authors suggested that the beneficial effects of this medium may be due to the relatively low osmolarity and the absence of differentiating factors present in bovine sera (Tanaka et al., 2006).

The adrenocorticotropic hormone (ACTH) has been employed by some to improve mESCs culture conditions. Ogawa et al. found that small concentrations of ACTH favoured clonal propagation of mESCs when added to the medium containing KoSR, and this compound was also able to maintain pluripotency of embryonic stem cells during several passages (Ogawa et al., 2004). In 2006, Wakayama et al. used the beneficial properties shown by ACTH and demonstrated that this factor facilitated the establishment of ESCs lines from isolated blastomeres with high success rates (Wakayama et al., 2007).

One important point to consider when culturing mESCs is that they should be seeded in high density in order to favour communication between them; but care should be taken to avoid overgrowth, which leads to differentiation. Medium needs to be change daily or when it turned yellowish, which indicates acidification. The culture medium should be stored at $4^{\circ} \mathrm{C}$, protected from the light and employed within the month of preparation.

When a cell line is obtained from another laboratory, it is advisable to culture them under the same conditions that they were derived because medium requirements can vary between different ESC lines. Variations in the original protocol could lead to eventual alterations of ESCs features. When conditions are not optimal, ESCs will in turn, acquire genetic lesions that will compromise their germ-line potential. Suboptimal conditions may include insufficient nutrients and growth factors, as well as leaving the cells for too long at high density without splitting them, which favours the differentiation into endoderm-like cells. To avoid loss of stemness state ESCs should be split every 2-3 days, and it is convenient to dissociate the stem cells colonies into single cells, since clumps of cells tend to differentiate (Nagy et al., 2003).

To maintain the undifferentiated state of ESCs, two types of feeder cells are most commonly used: primary culture of murine embryonic fibroblasts (MEFs) and STO mouse fibroblasts cell line. MEFs are obtained from 14.5-15.5 dpc mouse embryos. As primary cells, they have the advantage of being a very potent and reliable source of feeder cells. However, these cells show a limited life span in culture and must be replenish continuously from frozen stocks. What is more, they show a batch to batch variation, as not all embryos will produce goodquality fibroblasts (Nagy et al., 2003). Bryja et al. used MEFs from several strains of mice as feeder cells for mESCs isolation, but found no difference in their ability to support ESCs derivation; but what they did find was that earlier passages of MEFs performed better during the ESCs derivation protocols, since later passages of MEFs (P 3-5) showed lower viability and as a result, did not support the ESCs derivation as earlier passages (Bryja et al., 2006).

The STO cells were derived from SIM mice and are a thioguanine- and ouabain- resistant subline of fibroblasts. They have been used as a feeder layer for establishing ESCs from human, mouse and bovine origin as well as for embryonic germ cells. The advantage of using a cell line instead of MEFs for preparing the feeder layer is that these cells are easily grown and do not require a lengthy and tedious method to replenish frozen stocks. 
Feeder cells must be mitotically inactivated before use. This can be achieved in two ways: by treatment with Mitomycin C, a substance which crosslinks DNA and blocks cell proliferation; or by gamma-irradiation, that avoids the risk of carrying over mitomycin $\mathrm{C}$ from the feeder layer to the ESCs. The proper radiation dose must be determined in order to just arrest feeder cells growth without affecting seriously their viability, as ESCs need the growth factors released by fibroblasts (Zhou et al., 2005; Nagy et al., 2003).

The cells employed as feeder layer should be seeded preferentially 24 hours before use and its quality should be checked. Feeder cells are very important to achieve optimal growth conditions of ESCs, they should be plated in a good number but not in complete confluence (around $80 \%$ ), so they can spread across the culture plate.

\section{The incidence of genetics}

It is generally accepted that establishment of ESCs is influenced by species, strain within the same species and even retrieval methods. Even during the very first attempts to obtain mESCs, the strain of mice chosen was considered an important factor involved in the successful isolation of these cells (Sherman, 1975a).

Almost all the mESCs lines in current use have been derived from the 129 strain, known by bibliography as the most permissive strain, with a 30\% frequency of establishment. The low frequency of ES cell production employing other mouse strains compared with the 129 suggests an undefined genetic difference in this strain, possibly related to the high incidence of spontaneous testicular teratomas and teratocarcinomas that presents (Baharvand and Matthaei, 2004; Tanimoto et al., 2008). Derivation of ESCs is strongly mouse straindependent, and usually, the efficiency of derivation in strains other than 129 strain does not exceed 10\% (McWhir et al., 1996).

Genetic background is very important in several studies using experimental animals and so, establishment of mESCs lines from a variety of inbred and mutant mouse strains is desirable for wider utilization of ESCs (Kawase et al., 1994). Since the use of aged ESCs lines can lead to poor germ-line contribution in chimeras, the isolation of novel mESCs lines is also important (Baharvand and Matthaei, 2004).

Although the genetic background of the strain chosen for the obtaining of mESCs plays an important role, the establishment of a line from a particular strain also depends on the culture conditions employed. Kawase et al. could establish many ESCs lines from the mouse strain C57BL/6, but they had difficulties when it came to obtain lines from Balb-c employing the same culture medium. Similarly, Baharvand and Matthaei produced two lines from C57BL/ 6 but needed to use five times the concentration of LIF in the ES medium to obtain embryonic stem cells from Balb-c mice (Baharvand and Matthaei, 2004; Kawase et al., 1994). In the case of F1 hybrids or mixed hybrid genetic background, the success rate of establishing ESCs lines is very high (Nagy et al., 2003). Improving culture conditions, Lee et al. obtained mESCs lines from C57BL/6xDBA2 hybrid mice (B6D2F1), outbreed ICR strain and parthenogenetically activated embryos employing Ko-DMEM supplemented with a mixture of FBS and KoSR (Lee et al., 2006).

\section{Features of mouse embryonic stem cells}

The pluripotency of mESCs is evident from three main characteristics: 1) the cells can be injected into blastocysts to produce chimeric animals which carry these cells even at the 
germ-line level; 2) in vitro aggregation of ESCs leads to EBs formation producing derivatives of the three germ layers and; 3 ) inoculation of these pluripotent cells into immuno-deficient mice induces formation of teratomas.

Mouse ESCs self-renewal can be corroborated by staining the colonies for specific markers, such as SSEA-1, Oct4, Nanog or Sox2 (Fig. 2D-F). Presence of alkaline phosphatase activity and telomerase can also be measured as an indicator of the stemness state (Fig. 2B). Alkaline phosphatase (ALP) is an enzyme of restricted tissue distribution. In the adult mammal it is present in most tissues, but high activities are found only in: small intestine, kidney, bone and placenta. In the embryo, high activities are more widely distributed and all tissues are rich in ALP at early stages of development. It has been seen that high levels of ALP are characteristics of ECC, whereas the somatic cells that differentiate from the ALP-rich stem cells exhibit low activity (Berstine et al., 1973). In a similar manner, telomerase activity is diminished in adult cells but it is upregulated in embryonic stem cells. Telomerase activity and telomere maintenance are associated with immortality of cells. As stem cells have elongated proliferative capacity, they need a mechanism to maintain telomere length through many cell divisions (Hiyama and Hiyama, 2007).

When mESCs are observed under the light microscope, they are seen as part of spindle to round-shape colonies with smooth edges. The colonies are compacted; a feature apparently mediated by desmosome-like junctions, being thickened at the centre and thinned out towards the periphery (Fig. 2A). These cells grow in a multilayer manner, lack contact inhibition and anchorage dependence, and possess big nuclei surrounded by scarce cytoplasm, with prominent dark nucleoli (Fig. 2C) (Baharvand and Matthaei, 2003; Wobus and Boheler, 2005).

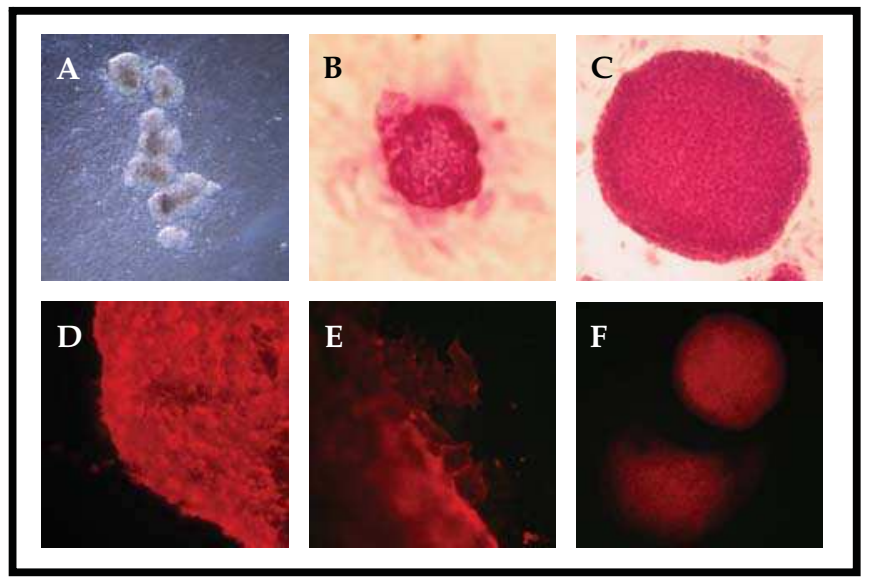

Fig. 2. Features of murine embryonic stem cells.

A) Mouse ESCs colonies; B) ALP staining; C) Mouse ESCs colony stained with hematoxylineosin showing the high nucleus/cytoplasm ratio; D) Expression of the cell surface marker SSEA-1; E) Extensions emitted by cells located at the edge of the mESCs colony; F) Nuclear staining pattern of Oct 4 in mESCs colonies

Baharvand and Matthaei have brought light into mESCs structure by means of electron microscopy analysis. They have seen that the ultrastructural characteristics of mESCs are similar to the ICM of mouse blastocysts. 
The mESCs cultured on a feeder layer of MEFs were seen well polarized, with its organelles in close proximity to the MEFs and some extensions of different length and microvilli projected to the feeder cells. Coated vesicles were abundant and were probably related to protein absorption. When attention was directed to MEFs, it was seen that they showed prominent Golgi complexes, and rough endoplasmic reticulum, which may be indicative of increased protein synthesis and secretion. Since MEFs prevent mESCs from differentiating, it is assumed that they secrete proteins that are important to maintain an undifferentiated state (Baharvand and Matthaei, 2003). When staining of mESCs with the cell surface marker SSEA-1 was carried out in our laboratory, the extensions projected to the MEFs mentioned above were observed, supporting this information (Fig. 2E) (Fagundez et al., 2009).

\section{Embryo stages capable of giving rise to mESCs}

The obtainment of mESCs is not only restricted to the blastocysts stage, since morulae have demonstrated being capable of forming mESCs colonies when co-culture with feeder cells. When Tesar cultured morulae, the ones that attached to the feeder layer produced outgrowths within a few days; however, the ones that did not continued with its development to blastocyst-stage. When morula-stage embryos were seeded without feeder layers onto gelatine-coated culture dishes, they failed to produce stem cells colonies. The embryos flattened out showing differentiation with presence of trophoblast giant cells. These findings show that employment of certain feeder layers may impose some restraints on further differentiation (Tesar, 2005).

In 1996, Delhaise et al. first reported the establishment of one ESCs line from isolated blastomeres of pre-compacted 8-cell stage embryos separated by disaggregation, but it was not able to germ-line transmission in chimeric mice. Ten years later, Chung et al. could isolate blastomeres from 8-cell embryos and culture them over a feeder layer of mESCs, obtaining 5 lines. The authors assured that co-culture with feeder cells was critical for the success of the system employed. Despite being successful in the isolation, the establishment rate was quite low, of about $4 \%$ (Chung et al., 2006). However, Wakayama et al. derived mESCs lines from single blastomeres obtained by biopsy from 2-, 4- and 8-cell stage mouse hybrids embryos with a high success rate of $14-69 \%$. Contrarily to the results obtained by Tesar with morulae seeding, all the blastomeres developed to blastocysts when plated onto MEFs before forming mESCs colonies (Wakayama et al., 2007). The efficiency in establishing ESCs lines from blastomeres of 2-, 4- and 8-cell embryos decreased according to the stage, being higher when they came from 2-cell stage embryos. These results demonstrate a pattern indicating that only 1 or 2 , but not all blastomeres from each embryonic stage are capable of deriving ESCs, which might suggest that sister blastomeres are in general not equally competent for establishing ES cells lines (Lorthongpanich et al., 2008; Wakayama et al., 2007). Lorthongpanich et al. could establish ESCs lines from isolated blastomeres of 2-cell stage embryos from CD-1 outbred mice strain but were unable to obtain lines from blastomeres coming from 4-cell stage embryos (Lorthongpanich et al., 2008).

The pre-blastocyst period in the mouse development constitutes a stage in which blastomeres are not yet committed to either the ICM or the trophoectodermal lineage. It is therefore conceivable that ESCs lines derived from morulae or earlier cleavage stage embryos might originate before cells were committed to one or other of these two lineages and thus exhibit a wider developmental potential than those of ICM or epiblast origin. Alternatively, permissiveness for ESCs derivation could be restricted to a specific stage of 
early development to which embryos must progress irrespective of the time they are explanted (Tesar, 2005).

In many of the cases when karyotype was perfomed, the established ESCs lines showed that they were male. One possible reason is that $X Y$ lines are relatively more stable, while $X X$ lines are unstable and have a tendency to become XO (Baharvand and Matthaei, 2004; Kawase et al., 1994). However, the majority of the lines obtained by Tesar were found to be XX (Tesar, 2005).

\section{Differentiation of mESCs}

When factors that maintain the stemness of ESCs are removed, they are capable of differentiate into a wide range of cell types derived from the germ layers: ectoderm, mesoderm and endoderm. This differentiation can be achieved by formation of embryoid bodies (EBs), which were defined by Dang et al. as aggregates of differentiating cells derived from one or more pluripotent stem cells that form or has the potential to form cells from each of the three embryonic germ layers (Dang et al., 2002).

The differentiation state acquired by EBs is often affected by the culture conditions at which they are exposed to. In some occasions, growth factors are added to the medium to promote differentiation to the desired cell type, such as: basic fibroblast growth factor (bFGF), transforming growth factor $\beta$ (TGF $\beta$ ), activin-A, bone morphogenetic protein 4 (BMP4), hepatocyte growth factor (HGF), epidermal growth factor (EGF), nerve growth factor (NGF), and retinoc acid (RA) (Kurosawa, 2007).

The three-dimensional cell aggregate formed by the EB facilitates multicellular interactions where cell to cell contact and gap junctions are established. An EB can model the processes of cell differentiation produced during early mammalian development (Kurosawa, 2007). Synchronous differentiation of EBs recapitulates organ-specific development and it is achieved in culture by formation of uniformly sized EBs (Ezekiel et al., 2007). There are some results which indicate that prior to day 3, EBs in suspension culture are, in terms of development, equivalent to pregastrulation-stage embryos. Between days 3 and 5, the EBs contain cell types present in embryos during gastrulation. Since day 6, these cell aggregates show similarities to embryos in the stage of early organogenesis (Ezekiel et al., 2007). However, EB differentiation does not reconstitute the complete array of embryonic development showing no "body plan", and formation of the primitive streak and cell movements associated to gastrulation do not occur (Jackson et al., 2010; Rippon and Bishop, 2004).

There are a variety of methods proposed to induce EB formation. All of these protocols were created to promote the efficient and reproducible obtainment of the cell types desired, as the pattern and efficiency of differentiation are affected by parameters like ESCs density, media components (aminoacids, growth factors and extracellular matrix proteins), $\mathrm{pH}$ and osmolarity, as well as the quality and type of serum employ (Wobus and Boheler, 2005).

A common technique is to simply deprive ESCs from the feeder cells or the presence of LIF, and culture them under conditions that initially prevent their adherence to the culture dishes. However, this is not always sufficient to obtain the expected results as will be discussed later.

The embryoid bodies are classified as simple or cystic according to the stage of differentiation achieved. In general, after 2 to 4 days of culture in suspension, EBs resemble a morula-like structure and are called simple EBs. By days 4-5, a cavity is formed inside the cell aggregates giving rise to cystic EBs, which look like an embryo in the blastula or egg 
cylinder stage. This kind of EBs consists of a double-layered structure, with an inner ectodermal layer and an outer layer of endoderm, enclosing the cavity (Fig. 3A). Commonly, after 8-10 days in suspension culture, structures homologous to the visceral yolk sac of postimplantation embryos appear in the cystics EBs (Fig. 3B,C) (Koike et al., 2007; Kurosawa, 2007).
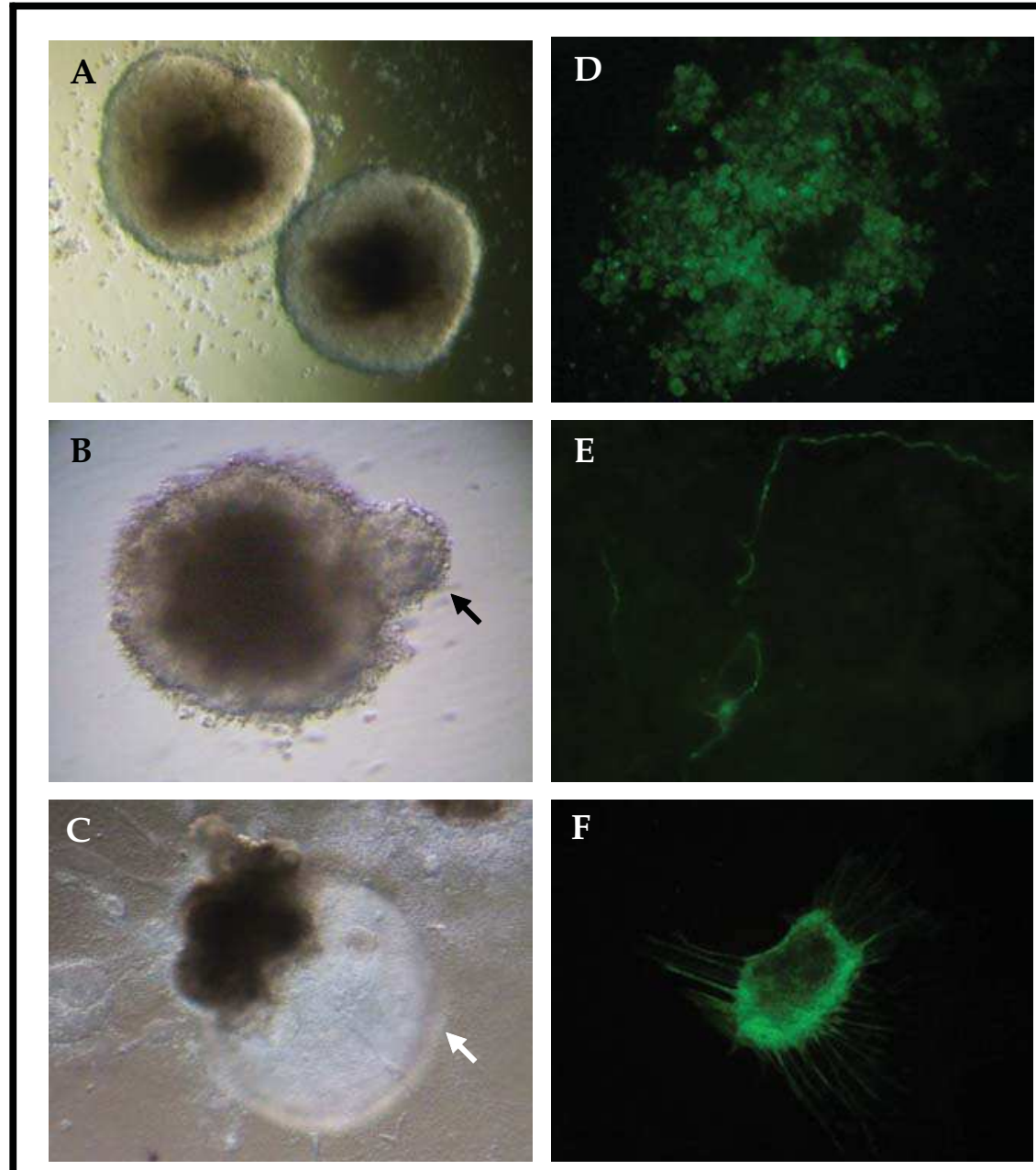

Fig. 3. Differentiation of mESC by means of embryoid bodies.

A) EBs of well-defined borders; B) and C) EBs showing yolk sac-like structures; D) - F) Immunocytochemistry of EB-derived cells stained for presence of $\alpha$-fetoprotein, $\beta$-III-tubulin and muscle actin, respectively

The majority of the methods utilized for EB differentiation studies involve: 1) production of EBs in suspension culture in absence of anti-differentiation factors; 2) growth of EBs on 
gelatine-coated culture plates; and 3) exposure of EBs to inducer agents to obtain a specific cell type.

The differentiation status acquired by EBs is markedly affected by the culture conditions employed and this is the reason why researches have been working in the development of new methods to improve EBs obtainment. A short description of the most common procedures is provided next.

Hanging drop culture. It is the most popular technique as it allows the formation of homogenous-sized EBs from a known number of ESCs. Generally, small drops containing 400-1000 ESCs are placed on the lid of a $100 \mathrm{~mm}$ Petri dish. The lid is then inverted to permit the aggregation of the cells at the bottom of the drop, and placed over a culture dish filled with PBS to avoid drops from drying out. After a few days, EBs are collected and cultured in suspension in a non-adherent surface dish. The EBs can be left there to further differentiation or transferred onto gelatine-coated plates (Kurosawa, 2007).

Suspension culture in bacterial-grade dishes. A suspension with a minimum of $10^{3}$ ESCs is seeded into a bacterial grade-dish. The cells do not attach to the plastic surface of the dish; instead they stick to each other forming aggregates that will give rise to EBs (Kurosawa, 2007). Another way to form EBs employing these plates is to culture the whole colonies of mESCs during varying periods of time (Fagundez et al., 2009). Unfortunately, both of these methods produce heterogeneous EBs with distinct degrees of differentiation. However, when the objective of EB formation is just to corroborate in vitro pluripotency of mESCs and the differentiation status acquired is not of great importance, this seems to be a good approach since the hanging drop (HD) method is not always easy to perform, and the results could also be variable. In our laboratory we were not able to form EBs with HD technique, as cells were unable to group and failed to produce three-dimensional aggregates.

Although generation of EBs in suspension culture employing whole ESCs colonies has some disadvantages, it seems possible that the proximity established among cells when growing together could be an important factor favouring the differentiation process, since cell to cell contact plays a major role in the early stages of embryonic development (Choi et al., 2005; Fagundez et al., 2009).

Semisolid suspension culture. It was originally employed to obtain cell aggregates of clonal origin. A medium with methylcellulose is used to obtain a semisolid consistence which permits ESCs to remain in isolation. In this way, single cells are not able to coalesce and every one of them develops into an EB. When the culture medium is changed for a standard one, without methylcellulose, the resulting EBs fuse into larger structures. This method has been used for the study of haematopoietic differentiation, endothelial cells and in haematopoietic colony-forming assays (Kurosawa, 2007).

Suspension culture in low-adherence vessels. This technique involves the use of lowadherence containers to produce EBs. A defined number of ESCs are placed in a 96-well plate of round bottom or in a polypropylene $1.5 \mathrm{ml}$-conical tube. The vessels concentrate the cells at the bottom, promoting cell aggregation and favouring contact with each other. After a few days of culture, a large EB is formed. Similarly to the hanging drop method, these two techniques allow the formation of uniform EBs from a determined number of cells (Kurosawa, 2007; Kurosawa et al., 2003; Ezekiel et al., 2007).

Generation of EBs on a STO feeder layer. Zhou et al. demonstrated that EBs can be formed from mESCs cultured on a low density of STO feeder cells, indicating that they can not only 
maintain undifferentiated mESCs, but also allow the formation of typical EBs. The generation of EBs by this method involves three steps: formation of compact cell aggregates, production of simple EBs, and generation of cystic EBs in suspension culture on bacterialgrade dishes. The embryoid bodies-derived cells obtained differentiated into cardiac, hepatic and neural cells with specific inducers (Zhou et al., 2005).

Embryoid bodies recapitulate many aspects of lineage-specific differentiation programmes as well as temporal and spatial gene expression patterns of early embryogenesis. Therefore, the EBs provide a valuable tool for investigating embryonic development at the cellular and molecular level (Zhou et al., 2005). During their in vitro maturation, mESCs undergo morphological changes and acquire various molecular markers of differentiated cells (Fig. 3D-F) (Itskovitz-Eldor et al., 2000). Leahy et al. employed developmentally regulated marker genes to compare the temporal and spatial relationship between differentiation of EBs and mouse postimplantation embryos. Their experiments demonstrated that the appearance of developmental markers and their overall distribution in EBs is strictly correlated with their expression patterns observed during specific stages of embryogenesis (Leahy et al., 1999).

Koike et al. studied the expression shifts of two genes that are highly expressed in undifferentiated ESCs, Oct4 and Rex-1, during formation of EBs. The expression levels of these two genes almost disappeared by day 5 of EB culture. These authors induced EB formation under different conditions starting from the same cell number of ESCs and found variations in the morphological appearance of the cell aggregates. They also found that the expression of GATA-4, a differentiation marker, increased during culture, but its expression profile varied more widely than Oct4 and Rex-1 according to the types of EBs. This suggests that the progress of differentiation in the distinct EBs is not homogenous. The culture conditions for EB formation, such as cell number and density, and culture configurations seem to be involved in the differentiation status of the resulting EBs (Koike et al., 2007).

As mentioned above, differentiation of ESCs by means of EB formation recapitulates changes in the embryonic development, and factors with main roles during early embryogenesis might be involved in the production of EBs. Mutual cell to cell interactions are important for the differentiation of stem cells into the cell types derived from the three germ layers. Cell-cell contact and apoptosis are very important during the early developmental stages and are expected to be found during the formation of embryoid bodies (Choi et al., 2005; Doetschman et al., 1985). Apoptosis is a natural process of development and several studies have revealed that apoptosis-related genes are involved in the differentiation of ESCs to EBs (Choi et al., 2005). During EB formation, multiple foci of cell death appear to finally merge into a single central cavity surrounded by a monolayer of primitive ectoderm cells (Fig. 4C,D). After aggregation of ESCs, the more external cells differentiate to primitive endoderm followed by visceral and parietal endoderm. Unlike normal embryos, endodermal cells are located in the outer surface of the EBs and are connected via junctional complexes showing numerous microvilli (Karbanova and Mokry, 2002; Rodda et al., 2002). Along with the establishment of the extraembryonic endoderm lineage a basement membrane is deposited between the pluripotent cells and the endoderm. It is proposed that this membrane induces an alteration in the pluripotent state of cells, such that the ones in contact with the membrane survive and reorganize to a columnar epithelium of primitive ectoderm, whereas the cells located at the centre and apart from the extracellular matrix undergo cell death and form a cavity (Rodda et al., 2002). In mice, this basal membrane is called Reichert's membrane and is composed primarily by collagen IV 
and glycoproteins, and it is located between parietal endoderm cells and trophoblast cells in rodent embryos. Reichert-like basement membrane deposits are often seen during the first days of EB culture and its presence can be identified by Periodic Acid Shiff (PAS) reaction (Fig. 4A,B) (Fagundez et al., 2009; Zhou et al., 2005).

There are different types of culture media that can be employed to induce formation of EBs and results vary according to the medium chosen and whether they are supplemented either with FBS or Ko-SR. As mentioned earlier, FBS contains pro-differentiation factors which make it a useful tool in differentiation protocols (Fagundez et al., 2009). Although some researchers were able to obtain EBs in a serum-free media (Bettiol et al., 2007; Taha and Valojerdi, 2008) it is generally accepted that at least small amounts of FBS are needed to favour differentiation, and no EBs are obtained in complete absence of serum (Mansergh et al., 2009).

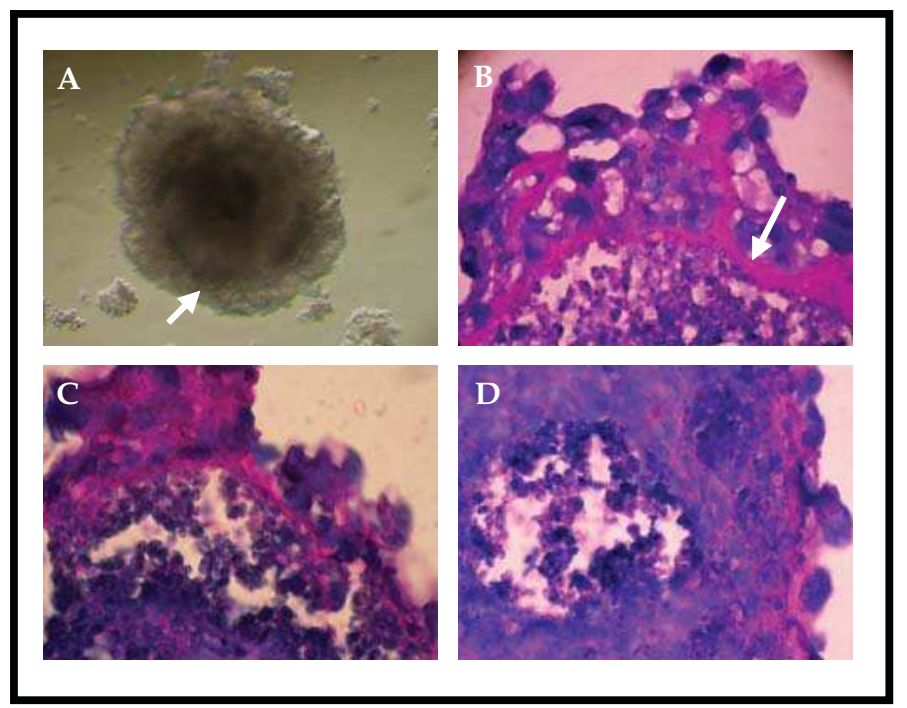

Fig. 4. Histology of embryoid bodies.

A) Deposits of Reichert-like basement membrane (arrow); B) PAS staining showing these deposits (arrow); C) and D) Peripheral and central cavities originated during EB formation

\section{Teratoma formation}

Teratomas are naturally occurring tumours that contain chaotic associations of structures resembling normal tissues of the three germ layers including glandular epithelium, cartilage, bone, smooth and striated muscle, as well as neural and stratified squamous epithelium; nevertheless they do not show the ordered and appropriate location of tissues as would be found in normal embryogenesis (Aleckovic and Simon, 2008; Berstine et al., 1973). Teratomas are classified by their content in solid, containing only tissues; cystic, with pockets of fluid; or mixed, containing a combination of both solid and cystic components (Aleckovic and Simon, 2008).

Teratomas can also be experimentally induced in mice injecting pluripotent stem cells into growth permissive ectopic sites. Embryonic stem cells are generally transplanted into 
immuno-deficient mice leading to the formation of palpable tumours at the graft site, which are normally allowed to develop for 6-10 weeks before its remotion for analysis. Different strains of mice have been used to study the in vivo potential of ESCs, but little is known about the influence of the strain of the immuno-deficient mice on teratoma formation. There is also no evidence that the specific number of ESCs implanted has any effect on developmental processes in teratomas; however, no teratoma was observed when an inferior number from $50000 \mathrm{mESC}$ sere transplanted into the hearts of immuno-deficient mice (Nussbaum et al., 2007). Generally, a number of $10^{3}-10^{6}$ embryonic stem cells are injected in order to ensure teratoma formation (Aleckovic and Simon, 2008). Experiments of ESCs injections have demonstrated that these cells behave differently according to the site of transplantation, showing variation on growth rate and cell differentiation of the teratomas obtained. For example, cells grafted into the intrahepatic location produced larger tumours in a short period of time consisting of a mixture of differentiated and immature tissues, whereas cells transplanted subcutaneously formed smaller teratomas composed basically of well differentiated cells, but took longer to develop (Cooke et al., 2006). Some studies indicate that local environment cues from the tissue in which ESCs are transplanted may influence in the ability of these cells to differentiate. It has been reported that mESCs produce a greater ratio of cartilaginous tissues in teratomas formed in the knee comparing to cells grafted into the subcutaneous space. Therefore, it seems possible that implanted cells are more likely to differentiate into tissues resembling their surroundings, probably due to local environmental signals (Przyborski, 2005; Wakitani et al., 2003). However, transplanted ESCs do not always differentiate into phenotypes corresponding to those of implantation site (Deacon et al., 1998).

\section{Molecular aspects of mESCs pluripotency}

Pluripotency is the ability to give rise to all cells of the organism (Keller, 2005). In embryonic stem cells it is mainly orchestrated by Oct4, Nanog and Sox2, the earliest-expressed set of genes known to maintain pluripotency. They work in conjunction with other transcription factors to specify the pluripotent state and thus constitute the basis of a transcription hierarchy (Boyer et al., 2006).

The property of self-renewal shown by ESCs depends on a stoichiometric balance among various signalling molecules and if an imbalance in any of them occurs, ESCs identity can be lost (Wobus and Boheler, 2005). Deprivation of Oct4 or a reduction to less than $50 \%$ of its normal expression level causes inappropriate differentiation of ESCs into trophoectoderm through upregulation of $C d x 2$, one of its target genes; whereas a less than two-fold increase results in formation of primitive endoderm and mesoderm (Johnson et al., 2006; Masui, 2010; Nichols et al., 1998; Niwa, 2001; Niwa et al., 2000). Oct4 deficient embryos (Oct4 -) develop to a stage that resembles a blastocyst with cells allocated inside them but which not constitute a real ICM since these cells lack pluripotency and are composed of trophoectoderm cells, resulting in peri-implantation developmental arrest. As expected, these structures cannot be employed for production of ESCs lines (Boiani and Scholer, 2005; Johnson et al., 2006). Different experiments have shown that Oct4 is not sufficient for the maintenance of pluripontency, because forced expression fails to give rise to mESCs (Johnson et al., 2006). However, this is not the case of Nanog, as forced expression of this gene seems to make mESCs more resistant to spontaneous differentiation in the absence of LIF. The persistence of Nanog apparently delays the differentiation of ESCs increasing the 
threshold of differentiation, but do not completely abolish it. Nanog-null ESCs can be established and still preserve pluripotency but with an increasing tendency to differentiate (Chambers et al., 2007). Nanog is expressed throughout the pluripotent cells of the ICM but its expression is decreased in extraembryonic lineages and in pluripotent cells of the periimplantation embryo. This leads to the hypothesis that one of the major roles of Nanog might be repression of GATA-6, responsible for the differentiation into extraembryonic endoderm (Chazaud et al., 2006). Nanog \%-embryos cannot preserve the pluripotent lineage, and as a consequence, arrest at peri-implantation. The ICM of these embryos, as well as Nanog-deficient ESCs, turn into parietal endoderm cells (Boiani and Scholer, 2005; Johnson et al., 2006). Sox $\%$ embryos arrest at similar time that Oct4 $\%$ and Nanog $\%$ embryos do. Blastocyst-like structures are formed, but lack primitive ectoderm. Therefore, Sox 2 - blastocysts are incapable of ESCs derivation. As Oct4 and Nanog, Sox2 plays an important role in the conservation of pluripotency, but its expression is not restricted to pluripotent cells; early primitive ectoderm, anterior primitive endoderm, germ cells and multipotent extraembryonic ectoderm cells also count with the presence of this gene (Boyer et al., 2006; Johnson et al., 2006).

In mouse embryonic stem cells, the maintenance of pluripotency is also regulated by the signal transducer and activator of transcription 3 (STAT3), whose function is triggered by LIF, which binds to the LIF receptor to dimerize with gp130, resulting in the phosphorylation of STAT3 via Janus kinase (JAK) activation. The phosphorylated STAT3 dimerizes and translocates to the nucleus, acting as a transcription factor to activate target genes which include essential genes to maintain the pluripotent cell phenotype (Boiani and Scholer, 2005; Johnson et al., 2006; Masui, 2010; Niwa, 2001). Repression of STAT3 results in differentiation, whereas its artificial activation is sufficient to maintain pluripotency of the cells in absence of LIF (Masui, 2010). Apart from the LIF-STAT3 pathway, the pluripotency of mESCs is also regulated by members of the superfamily of the TGF $\beta$, which include activin and BMP. The BMP4, for example, activates Smad1, which upregulates the expression of the inhibitor of DNA-binding genes (Id) which, in turn, suppresses differentiation along with the LIF signal (Masui, 2010).

The Wnt signalling also has an important function, since administration of Wnt proteins can contribute to preserving the pluripotency of ESCs (Masui, 2010).

The chromatin of ESCs displays characteristics of transcriptionally permissive euchromatin, like acetylated histone modifications and increased accessibility to nucleases. On the contrary, lineage specification is distinguished by a decreased in acetylation and an increased in heterochromatin formation, indicating that a restriction in developmental potential is associated with a marked decrease in genomic plasticity. It is possible then that the balance between pluripotency and lineage commitment is regulated by genetic and epigenetic factors as well (Boyer et al., 2006).

\section{The use of mESCs for research purposes}

Mouse ESCs have had a great impact on many fields of research. One of the advantages of mESCs is that they can be genetically modified. When ESCs are placed into a blastocyst, they can contribute to all the lineages of the embryo including the germ line. This property makes mESCs a useful tool to produce precise alterations in the genome to study the phenotypic effects of these alterations in vivo, generating "knock out" and "knock in" transgenic animals (Jackson et al., 2010; Rippon and Bishop, 2004; Williams et al., 1988). By 
means of transgenic techniques, they have also proved their potential for modelling human diseases, providing an opportunity to unravel biochemical, genetic and/or physiological causes of a plethora of pathologies.

Murine embryonic stem cells have the potential to produce unlimited numbers of cells in culture which can be used to elucidate the underlying mechanisms of pluripotency and cell lineage specification, allowing comprehension of processes in developmental biology and regulation of genes during mammalian embryogenesis.

The plasticity of these cells makes them useful to study spatial and temporal relationships that determine cell, tissue and organ development.

Mouse embryonic stem cells have become very useful for biomedical research and have played an important part in clarifying many of the signal transduction pathways that regulate progression through the cell cycle.

Since its isolation in 1981, mouse embryonic stem cells have served as an invaluable instrument to explain many processes of the organism extrapolating the knowledge acquired to the human field, and they will continue to do so in the times to come.

\section{References}

Aleckovic, M. and Simon, C. (2008). Is teratoma formation in stem cell research a characterization tool or a window to developmental biology? Reproductive Biomedicine Online, 17, 2, (Aug) (270-280), ISSN 1472-6483

Baharvand, H. and Matthaei, K. I. (2003). The ultrastructure of mouse embryonic stem cells. Reproductive Biomedicine Online, 7, 3, (Oct) (330-335), ISSN 1472-6483

Baharvand, H. and Matthaei, K. I. (2004). Culture condition difference for establishment of new embryonic stem cell lines from the C57BL/6 and BALB/c mouse strains. In Vitro Cell Dev Biol Anim, 40, 3-4, (Mar-Apr) (76-81), ISSN 1071-2690

Berstine, E. G.; Hooper, M. L.; Grandchamp, S. and Ephrussi, B. (1973). Alkaline phosphatase activity in mouse teratoma. Proc Natl Acad Sci U S A, 70, 12, (Dec) (3899-3903), ISSN 1091-6490

Bettiol, E.; Sartiani, L.; Chicha, L.; Krause, K. H.; Cerbai, E. and Jaconi, M. E. (2007). Fetal bovine serum enables cardiac differentiation of human embryonic stem cells. Differentiation, 75, 8, (Oct) (669-681), ISSN 0301-4681

Boiani, M. and Scholer, H. R. (2005). Regulatory networks in embryo-derived pluripotent stem cells. Nat Rev Mol Cell Biol, 6, 11, (Nov) (872-884), ISSN 1471-0072

Boyer, L. A.; Mathur, D. and Jaenisch, R. (2006). Molecular control of pluripotency. Curr Opin Genet Dev, 16, 5, (Oct) (455-462), ISSN 0959-437X

Bryja, V.; Bonilla, S.; Cajanek, L.; Parish, C. L.; Schwartz, C. M.; Luo, Y.; Rao, M. S. and Arenas, E. (2006). An efficient method for the derivation of mouse embryonic stem cells. Stem Cells, 24, 4, (Apr) (844-849), ISSN 1549-4918

Buehr, M. and Smith, A. (2003). Genesis of embryonic stem cells. Philos Trans R Soc Lond B Biol Sci, 358, 1436, (Aug) (1397-1402; discussion 1402), ISSN 0962-8436

Chambers, I.; Silva, J.; Colby, D.; Nichols, J.; Nijmeijer, B.; Robertson, M.; Vrana, J.; Jones, K.; Grotewold, L. and Smith, A. (2007). Nanog safeguards pluripotency and mediates germline development. Nature, 450, 7173, (Dec) (1230-1234), ISSN 0028-0836

Chazaud, C.; Yamanaka, Y.; Pawson, T. and Rossant, J. (2006). Early lineage segregation between epiblast and primitive endoderm in mouse blastocysts through the Grb2MAPK pathway. Dev Cell, 10, 5, (May) (615-624), ISSN 1534-5807 
Choi, D.; Lee, H. J.; Jee, S.; Jin, S.; Koo, S. K.; Paik, S. S.; Jung, S. C.; Hwang, S. Y.; Lee, K. S. and Oh, B. (2005). In vitro differentiation of mouse embryonic stem cells: enrichment of endodermal cells in the embryoid body. Stem Cells, 23, 6, (Jun-Jul) (817-827), ISSN 1549-4918

Chung, Y.; Klimanskaya, I.; Becker, S.; Marh, J.; Lu, S. J.; Johnson, J.; Meisner, L. and Lanza, R. (2006). Embryonic and extraembryonic stem cell lines derived from single mouse blastomeres. Nature, 439, 7073, (Jan) (216-219), ISSN 0028-0836

Cole, R. and Paul J. (1965). Properties of cultured preimplantation mouse and rabbit embryos and cell strains derived from them, In: Preimplantation Stages of Pregnancy: a Ciba Foundation Symposium, Wolstenholme G. and O'Connor M. (Eds), (82-112), Little Brown and Company, London.

Cooke, M. J.; Stojkovic, M. and Przyborski, S. A. (2006). Growth of teratomas derived from human pluripotent stem cells is influenced by the graft site. Stem Cells Dev, 15, 2, (Apr) (254-259), ISSN 1547-3287

Dang, S. M.; Kyba, M.; Perlingeiro, R.; Daley, G. Q. and Zandstra, P. W. (2002). Efficiency of embryoid body formation and hematopoietic development from embryonic stem cells in different culture systems. Biotechnol Bioeng, 78, 4, (May) (442-453), ISSN 0006-3592

Deacon, T.; Dinsmore, J.; Costantini, L. C.; Ratliff, J. and Isacson, O. (1998). Blastula-stage stem cells can differentiate into dopaminergic and serotonergic neurons after transplantation. Exp Neurol, 149, 1, (Jan) (28-41), ISSN 0014-4886

Doetschman, T. C.; Eistetter, H.; Katz, M.; Schmidt, W. and Kemler, R. (1985). The in vitro development of blastocyst-derived embryonic stem cell lines: formation of visceral yolk sac, blood islands and myocardium. J Embryol Exp Morphol, 87, (Jun) (27-45), ISSN 0022-0752

Evans, M. J. and Kaufman, M. H. (1981). Establishment in culture of pluripotential cells from mouse embryos. Nature, 292, 5819, (Jul) (154-156), ISSN 0028-0836

Ezekiel, U.; Muthuchamy, M.; Ryerse, J. and Heuertz, R. (2007). Single embryoid body formation in a multi-well plate. Electron J Biotechnol, 10, 2, (Apr) (328-335), ISSN 0717-3458

Fagundez, C. B.; Loresi, M. A.; Ojea Quintana, M. E.; Delcourt, S. M.; Testa, R.; Gogorza, S. J. and Argibay, P. F. (2009). A simple approach for mouse embryonic stem cells isolation and differentiation inducing embryoid body formation. Cell Biol Int, 33, 11, (Nov) (1196-1200), ISSN 1065-6995

Gardner, R. L. (1985). Regeneration of endoderm from primitive ectoderm in the mouse embryo: fact or artifact? J Embryol Exp Morphol, 88, (Aug) (303-326), ISSN 0022-0752

Gwatkin, R. B. (1966). Defined media and development of mammalian eggs in vitro. Ann N $Y$ Acad Sci, 139, 1, (Oct) (79-90), ISSN 0077-8923

Hiyama, E. and Hiyama, K. (2007). Telomere and telomerase in stem cells. Br J Cancer, 96, 7, (Apr) (1020-1024), ISSN 0007-0920

Itskovitz-Eldor, J.; Schuldiner, M.; Karsenti, D.; Eden, A.; Yanuka, O.; Amit, M.; Soreq, H. and Benvenisty, N. (2000). Differentiation of human embryonic stem cells into embryoid bodies compromising the three embryonic germ layers. Mol Med, 6, 2, (Feb) (88-95), ISSN 1076-1551

Jackson, M.; Taylor, A. H.; Jones, E. A. and Forrester, L. M. (2010). The culture of mouse embryonic stem cells and formation of embryoid bodies, In: Mouse Cell Culture: 
Methods in Molecular Biology 633, Ward A and Tosh D (Eds), (1-18), ISBN 1588297721, United Kingdom

Johnson, B. V.; Rathjen, J. and Rathjen, P. D. (2006). Transcriptional control of pluripotency: decisions in early development. Curr Opin Genet Dev, 16, 5, (Oct) (447-454), ISSN 0959-437X

Karbanova, J. and Mokry, J. (2002). Histological and histochemical analysis of embryoid bodies. Acta Histochem, 104, 4, (Feb) (361-365), ISSN 0065-1281

Kawase, E.; Suemori, H.; Takahashi, N.; Okazaki, K.; Hashimoto, K. and Nakatsuji, N. (1994). Strain difference in establishment of mouse embryonic stem (ES) cell lines. Int J Dev Biol, 38, 2, (Jun) (385-390), ISSN 0214-6282

Keller, G. (2005). Embryonic stem cell differentiation: emergence of a new era in biology and medicine. Genes Dev, 19, 10, (May) (1129-1155), ISSN 0890-9369

Koike, M.; Sakaki, S.; Amano, Y. and Kurosawa, H. (2007). Characterization of embryoid bodies of mouse embryonic stem cells formed under various culture conditions and estimation of differentiation status of such bodies. J Biosci Bioeng, 104, 4, (Oct) (294299), ISSN 1389-1723

Kurosawa, H. (2007). Methods for inducing embryoid body formation: in vitro differentiation system of embryonic stem cells. J Biosci Bioeng, 103, 5, (May) (389398), ISSN 1389-1723

Kurosawa, H.; Imamura, T.; Koike, M.; Sasaki, K. and Amano, Y. (2003). A simple method for forming embryoid body from mouse embryonic stem cells. J Biosci Bioeng, 96, 4, (Dec) (409-411), ISSN 1389-1723

Leahy, A.; Xiong, J. W.; Kuhnert, F. and Stuhlmann, H. (1999). Use of developmental marker genes to define temporal and spatial patterns of differentiation during embryoid body formation. J Exp Zool, 284, 1, (Jun) (67-81), ISSN 1932-5231

Lee, S. T.; Oh, S. W.; Kim, D. Y.; Han, J. Y.; Moon, S. Y. and Lim, J. M. (2006). Serum replacement with a growth factor-free synthetic substance in culture medium contributes to effective establishment of mouse embryonic stem cells of various origins. Fertil Steril, 86, 4 Suppl, (Oct) (1137-1145), ISSN 0015-0282

Lorthongpanich, C.; Yang, S. H.; Piotrowska-Nitsche, K.; Parnpai, R. and Chan, A. W. (2008). Development of single mouse blastomeres into blastocysts, outgrowths and the establishment of embryonic stem cells. Reproduction, 135, 6, (Jun) (805-813), ISSN 1470-1626

Mansergh, F. C.; Daly, C. S.; Hurley, A. L.; Wride, M. A.; Hunter, S. M. and Evans, M. J. (2009). Gene expression profiles during early differentiation of mouse embryonic stem cells. BMC Dev Biol, 9, (Jan), (5), ISSN 1471-213X

Martin, G. R. (1981). Isolation of a pluripotent cell line from early mouse embryos cultured in medium conditioned by teratocarcinoma stem cells. Proc Natl Acad Sci U S A, 78, 12, (Dec) (7634-7638), ISSN 1091-6490

Masui, S. (2010). Pluripotency maintenance mechanism of embryonic stem cells and reprogramming. Int J Hematol, 91, 3, (Apr) (360-372), ISSN 0925-5710

McWhir, J.; Schnieke, A. E.; Ansell, R.; Wallace, H.; Colman, A.; Scott, A. R. and Kind, A. J. (1996). Selective ablation of differentiated cells permits isolation of embryonic stem cell lines from murine embryos with a non-permissive genetic background. Nat Genet, 14, 2, (Oct) (223-226), ISSN 1061-4036 
Nagy, A.; Gertsenstein, M.; Vintersten, K. and Behringer, R. (2003). Manipulating the Mouse Embryo. A Laboratory Manual, Cold Spring Harbor Laboratory Press, ISBN 978087969591-0, United States

Nichols, J.; Zevnik, B.; Anastassiadis, K.; Niwa, H.; Klewe-Nebenius, D.; Chambers, I.; Scholer, H. and Smith, A. (1998). Formation of pluripotent stem cells in the mammalian embryo depends on the POU transcription factor Oct4. Cell, 95, 3, (Oct) (379-391), ISSN 0092-8674

Niwa, H. (2001). Molecular mechanism to maintain stem cell renewal of ES cells. Cell Struct Funct, 26, 3, (Jun) (137-148), ISSN 0386-7196

Niwa, H.; Miyazaki, J. and Smith, A. G. (2000). Quantitative expression of Oct-3/4 defines differentiation, dedifferentiation or self-renewal of ES cells. Nat Genet, 24, 4, (Apr) (372-376), ISSN 1061-4036

Nussbaum, J.; Minami, E.; Laflamme, M. A.; Virag, J. A.; Ware, C. B.; Masino, A.; Muskheli, V.; Pabon, L.; Reinecke, H. and Murry, C. E. (2007). Transplantation of undifferentiated murine embryonic stem cells in the heart: teratoma formation and immune response. Faseb J, 21, 7, (May) (1345-1357), ISSN 0892-6638

Ogawa, K.; Matsui, H.; Ohtsuka, S. and Niwa, H. (2004). A novel mechanism for regulating clonal propagation of mouse ES cells. Genes Cells, 9, 5, (May) (471-477), ISSN 13652443

Przyborski, S. A. (2005). Differentiation of human embryonic stem cells after transplantation in immune-deficient mice. Stem Cells, 23, 9, (Oct) (1242-1250), ISSN 1549-4918

Rippon, H. J. and Bishop, A. E. (2004). Embryonic stem cells. Cell Prolif, 37, 1, (Feb) (23-34), ISSN 0960-7722

Rodda, S. J.; Kavanagh, S. J.; Rathjen, J. and Rathjen, P. D. (2002). Embryonic stem cell differentiation and the analysis of mammalian development. Int J Dev Biol, 46, 4, (449-458), ISSN 0214-6282

Rossant, J. (2001). Stem cells from the Mammalian blastocyst. Stem Cells, 19, 6, (Nov) (477482),

Sherman, M. I. (1975a). The culture of cells derived from mouse blastocysts. Cell, 5, 4, (Aug) (343-349), ISSN 1549-4918

Sherman, M. I. (1975b). Long term culture of cells derived from mouse blastocysts. Differentiation, 3, 1-3, (Aug) (51-67), ISSN 0301-4681

Smith, A. G.; Heath, J. K.; Donaldson, D. D.; Wong, G. G.; Moreau, J.; Stahl, M. and Rogers, D. (1988). Inhibition of pluripotential embryonic stem cell differentiation by purified polypeptides. Nature, 336, 6200, (Dec) (688-690), ISSN 0028-0836

Taha, M. F. and Valojerdi, M. R. (2008). Effect of bone morphogenetic protein-4 on cardiac differentiation from mouse embryonic stem cells in serum-free and low-serum media. Int J Cardiol, 127, 1, (Jun) (78-87), ISSN 0167-5273

Tanaka, N.; Takeuchi, T.; Neri, Q. V.; Sills, E. S. and Palermo, G. D. (2006). Laser-assisted blastocyst dissection and subsequent cultivation of embryonic stem cells in a serum/cell free culture system: applications and preliminary results in a murine model. J Transl Med, 4, (May) (20), ISSN 1479-5876

Tanimoto, Y.; Iijima, S.; Hasegawa, Y.; Suzuki, Y.; Daitoku, Y.; Mizuno, S.; Ishige, T.; Kudo, T.; Takahashi, S.; Kunita, S.; Sugiyama, F. and Yagami, K. (2008). Embryonic stem cells derived from C57BL/6J and C57BL/6N mice. Comp Med, 58, 4, (Aug) (347352), ISSN 1532-0820 
Tesar, P. J. (2005). Derivation of germ-line-competent embryonic stem cell lines from preblastocyst mouse embryos. Proc Natl Acad Sci U S A, 102, 23, (Jun) (8239-8244), ISSN 1091-6490

Wakayama, S.; Hikichi, T.; Suetsugu, R.; Sakaide, Y.; Bui, H. T.; Mizutani, E. and Wakayama, T. (2007). Efficient establishment of mouse embryonic stem cell lines from single blastomeres and polar bodies. Stem Cells, 25, 4, (Apr) (986-993), ISSN 1549-4918

Wakitani, S.; Takaoka, K.; Hattori, T.; Miyazawa, N.; Iwanaga, T.; Takeda, S.; Watanabe, T. K. and Tanigami, A. (2003). Embryonic stem cells injected into the mouse knee joint form teratomas and subsequently destroy the joint. Rheumatology (Oxford), 42, 1, (Jan) (162-165), ISSN 1462-0324

Williams, R. L.; Hilton, D. J.; Pease, S.; Willson, T. A.; Stewart, C. L.; Gearing, D. P.; Wagner, E. F.; Metcalf, D.; Nicola, N. A. and Gough, N. M. (1988). Myeloid leukaemia inhibitory factor maintains the developmental potential of embryonic stem cells. Nature, 336, 6200, (Dec) (684-687), ISSN 0028-0836

Wobus, A. M. (2001). Potential of embryonic stem cells. Mol Aspects Med, 22, 3, (Jun) (149164), ISSN 0098-2997

Wobus, A. M. and Boheler, K. R. (2005). Embryonic stem cells: prospects for developmental biology and cell therapy. Physiol Rev, 85, 2, (Apr) (635-678), ISSN 0031-9333

Wobus, A. M.; Holzhausen, H.; Jakel, P. and Schoneich, J. (1984). Characterization of a pluripotent stem cell line derived from a mouse embryo. Exp Cell Res, 152, 1, (May) (212-219), ISSN 0014-4827

Zandstra, P. W.; Le, H. V.; Daley, G. Q.; Griffith, L. G. and Lauffenburger, D. A. (2000). Leukemia inhibitory factor (LIF) concentration modulates embryonic stem cell selfrenewal and differentiation independently of proliferation. Biotechnol Bioeng, 69, 6, (Sep) (607-617), ISSN 0006-3592

Zhou, Q. J.; Shao, J. Z.; Xiang, L. X.; Hu, R. Z.; Lu, Y. L.; Yao, H. and Dai, L. C. (2005). Generation of embryoid bodies from mouse embryonic stem cells cultured on STO feeder cells. Cell Biol Int, 29, 9, (Sep) (817-825), ISSN 1065-6995 


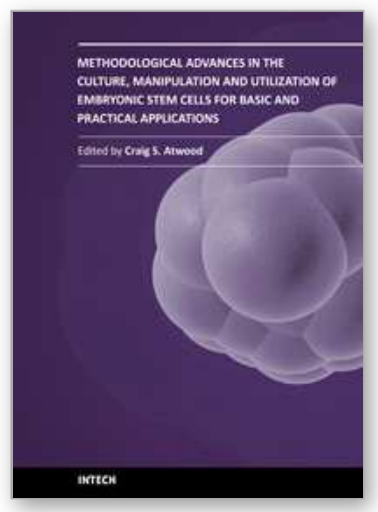

\author{
Methodological Advances in the Culture, Manipulation and \\ Utilization of Embryonic Stem Cells for Basic and Practical \\ Applications \\ Edited by Prof. Craig Atwood
}

ISBN 978-953-307-197-8

Hard cover, 506 pages

Publisher InTech

Published online 26, April, 2011

Published in print edition April, 2011

Pluripotent stem cells have the potential to revolutionise medicine, providing treatment options for a wide range of diseases and conditions that currently lack therapies or cures. This book describes methodological advances in the culture and manipulation of embryonic stem cells that will serve to bring this promise to practice.

\title{
How to reference
}

In order to correctly reference this scholarly work, feel free to copy and paste the following:

Carol Fagundez, Mónica Loresi, Stella Delcourt and Pablo Argibay (2011). Mouse Embryonic Stem Cells Basics from a Fertilized Zygote to These Promising Pluripotent Stem Cells, Methodological Advances in the Culture, Manipulation and Utilization of Embryonic Stem Cells for Basic and Practical Applications, Prof. Craig Atwood (Ed.), ISBN: 978-953-307-197-8, InTech, Available from:

http://www.intechopen.com/books/methodological-advances-in-the-culture-manipulation-and-utilization-ofembryonic-stem-cells-for-basic-and-practical-applications/mouse-embryonic-stem-cells-basics-from-afertilized-zygote-to-these-promising-pluripotent-stem-cells

\section{INTECH}

open science | open minds

\section{InTech Europe}

University Campus STeP Ri

Slavka Krautzeka 83/A

51000 Rijeka, Croatia

Phone: +385 (51) 770447

Fax: +385 (51) 686166

www.intechopen.com

\section{InTech China}

Unit 405, Office Block, Hotel Equatorial Shanghai

No.65, Yan An Road (West), Shanghai, 200040, China

中国上海市延安西路65号上海国际贵都大饭店办公楼 405 单元

Phone: +86-21-62489820

Fax: $+86-21-62489821$ 
(C) 2011 The Author(s). Licensee IntechOpen. This chapter is distributed under the terms of the Creative Commons Attribution-NonCommercialShareAlike-3.0 License, which permits use, distribution and reproduction for non-commercial purposes, provided the original is properly cited and derivative works building on this content are distributed under the same license. 